\title{
Health status utilities and the impact of pressure ulcers in long-term care residents in Ontario
}

\author{
Hla-Hla Thein • Tara Gomes • Murray D. Krahn • \\ Walter P. Wodchis
}

Accepted: 30 November 2009/Published online: 22 December 2009

(C) The Author(s) 2009. This article is published with open access at Springerlink.com

\begin{abstract}
Purpose To estimate health status utilities in long-term care (LTC) residents in Ontario, both with and without pressure ulcers (PUs), and to determine the impact of PU on health-related quality of life (HRQOL).

Methods A retrospective population-based study was carried out using Minimum Data Set (MDS) health assessment data among all residents in 89 LTC homes in
\end{abstract}

Author contributions Hla-Hla Thein, Murray Krahn, and Walter Wodchis contributed to the study concept and design, data analysis, and interpretation of data. Tara Gomes contributed to the data analysis. Hla-Hla Thein prepared the manuscript, and Murray Krahn and Walter Wodchis contributed to the revisions of the manuscript.

H.-H. Thein · M. D. Krahn

Toronto General Research Institute, University Health Network, Toronto, ON M5G 2C4, Canada

e-mail: rthein@uhnres.utoronto.ca

M. D. Krahn

e-mail: murray.krahn@theta.utoronto.ca

H.-H. Thein - M. D. Krahn · W. P. Wodchis

Toronto Health Economics and Technology Assessment

Collaborative (THETA), University of Toronto,

144 College Street, Room 600, Toronto, ON M5S 3M2,

Canada

T. Gomes

Medical Advisory Secretariat (MAS), Ontario Ministry of Health and Long-Term Care, Toronto, ON, Canada

e-mail: tara.gomes@ices.on.ca

T. Gomes · W. P. Wodchis

Institute for Clinical Evaluative Sciences, Toronto, ON, Canada

M. D. Krahn

Departments of Medicine and Health Policy, Management and Evaluation and Faculty of Pharmacy, University of Toronto,

155 College Street, 4th Floor, Toronto, ON M5T 3M6, Canada
Ontario who had a full MDS assessment between May 2004 and November 2007. The Minimum Data Set-Health Status Index (MDS-HSI) was used to measure HRQOL. A stepwise regression was used to determine the impact of PU on MDS-HSI scores.

Results A total of 1,498 (9\%) of 16,531 LTC residents had at least one stage II PU or higher. The mean \pm SD MDS-HSI scores of LTC residents without PU and those with PU were $0.36 \pm 0.17$ and $0.26 \pm 0.13$, respectively $(p<0.001)$. Factors associated with lower MDS-HSI scores included: older age; being female; having a PU;

\section{W. P. Wodchis $(\square)$}

Department of Health Policy, Management and Evaluation,

Faculty of Medicine, University of Toronto, Toronto,

ON, Canada

e-mail: walter.wodchis@utoronto.ca

W. P. Wodchis

Toronto Rehabilitation Institute, Toronto, ON, Canada

H.-H. Thein

Division of Clinical Decision-Making \& Health Care Research,

Division of General Internal Medicine, Toronto General

Hospital, 200 Elizabeth Street EN13-222A, Toronto,

ON M5G 2C4, Canada

T. Gomes

2075 Bayview Avenue, G-Wing, Toronto, ON M4N 3M5,

Canada 
recent hip fracture; multiple comorbid conditions; bedfast; incontinence; Changes in Health, End-stage disease and Symptoms and Signs; clinically important depression; treated with a turning/repositioning program; taking antipsychotic medications; and use of restraints.

Conclusions LTC residents with PU had slightly though statistically significantly lower HRQOL than those without PU. Comorbidity contributed substantially to the low HRQOL in these populations. Community-weighted MDS-HSI utilities for LTC residents are useful for costeffectiveness analyses and help guide health policy development.

Keywords Health-related quality of life . Long-term care $\cdot$ Minimum Data Set $\cdot$ Health Status Index . Ontario/Canada $\cdot$ Utilities

\section{Introduction}

Pressure ulcers (PUs) commonly occur in long-term care (LTC) residents and impose a significant financial as well as health burden on health care systems [1]. PUs usually develop over bony prominences on the body as a result of pressure, shearing forces, or friction [2, 3]. For LTC residents, the development of a PU is associated with many concomitant conditions and a range of symptoms. Qualitative work has shown that the impact of both PU and related treatments is wide ranging, with physical, emotional, social, and financial aspects affected, while pain, restricted activities, changes in body image, and the loss of independence/control are profound [4-7]. It is, therefore, important to quantify the impact of PU on an individual's health-related quality of life (HRQOL) [5]. While community-based preference (utility)-weighted HRQOL measures are a preferred measure of burden of illness [8], the impact of PU on utility-weighted HRQOL in LTC residents has not been quantified previously.

Current guidelines recommend the use of preferencebased measures (utilities) that represent community preferences for economic evaluations performed from the societal perspective [8]. Utilities measure health-related quality of life (HRQOL) on a scale of 0 (dead) to 1 (perfect health) providing information on the level and value of health states [9]. Population-based studies typically use multi-attribute or indirect HRQOL measures [10]. In this approach, health status is determined by responses to a multi-attribute health status classification system, and utility weights are assigned to each health state based on preference measurements taken from random samples of the general population (community preferences).
The Minimum Data Set (MDS) is used in over 19 countries (including mandated use in nearly all US nursing homes and several Canadian provinces) and is the most widely used health assessment instrument for institutional LTC settings [9]. Applications of data captured in the MDS include health care planning [10], case-mix [11], quality improvement [12], and outcome measurement [9, 13]. The MDS-derived utility-based HRQOL measure (Minimum Data Set-Health Status Index, MDS-HSI) has shown analogous group-level results with the Health Utilities Index 2 (HUI2) [14, 15]. By combining the health status assessment information from the MDS with multi-attribute HUI2 community-based population utility scores for various health states, the MDS-HSI measures community preferences for health states experienced by LTC residents. Our objectives were to use the MDS-HSI to estimate health status utilities in LTC residents in Ontario, both with and without PUs, and to determine the impact of PU on HRQOL.

\section{Methods}

Setting and population

All residents in 89 LTC homes in Ontario who had a full MDS assessment were included in this analysis. If a person had more than one full assessment, one was randomly selected. This sample was representative of the population in the 89 LTC homes during the study period between May 14, 2004 and November 7, 2007. The 89 homes were selected by the Ontario Ministry of Health and Long-Term Care as the first wave of implementation sites for the MDS and were chosen to be representative of geography, size, and ownership; all 620 Ontario homes will adopt the MDS by 2012 .

\section{Data sources}

\section{Minimum Data Set}

LTC population-based data from the MDS 2.0 Canadian version was used to derive MDS-HSI scores for LTC residents in Ontario. The reliability and validity of the MDS for clinical practice and research purposes have been demonstrated in several studies [16-19]. The MDS comprises over 400 items and includes detailed measures of clinical diagnoses and conditions and health status including cognition, self-care, mobility, sensation, emotion, and pain. Trained assessors completed MDS assessments, with the majority (68\%) including participation by residents and $27 \%$ including participation by both residents and their family. 


\section{Measures}

\section{Minimum Data Set-Health Status Index}

The MDS-HSI is based upon the Health Utilities Index Mark 2 (HUI2), encompassing six attributes to define health states: cognition, self-care, mobility, sensation (vision, hearing, and speech), emotion, and pain [20-23]. Each HUI2 attribute has four or five levels, ranging from severely impaired to no impairment/normal. The HUI2 uses standard gamble-based Canadian community preference weights to obtain a cardinal index of HRQOL with a range of -0.02 through 1.0. A score of 0 represents dead and 1.0 represents the best possible health one could expect to achieve [20-23]. A negative score implies health states worse than dead. A difference of 0.03 or more on an overall score is considered clinically important based on crosssectional and longitudinal comparisons of known groups [24]. The MDS-HSI is a validated preference-based utility score that can be generated from routine MDS assessments. The MDS-HSI is derived by mapping specific MDS elements to each attribute of the HUI2 classification system and then assigning scores using the HUI2 preference weights [17]. Earlier work has established a relationship between the HUI2 and the MDS-HSI in older communitydwelling and institutional LTC clients [15]. The MDS-HSI has been shown to have good construct and convergent validity (i.e. MDS-HSI scores and related summary functioning scores are highly correlated), as well as good discriminant validity measured in different populations $[14,15]$.

Details of the derivation of the MDS-HSI can be found in Wodchis et al. [14, 15]. Similar to the HUI2 measure, the MDS-HSI was derived in two steps: first, relevant items from the MDS assessment were mapped onto the HUI2 health status classification system; second, subjects were assigned MDS-HSI scores using the Canadian HUI2 community preference weights [21-23].

\section{Measurement}

The MDS records the number of PUs at stage I through IV [25]. We categorized residents as having a PU if they had one or more PUs at stage II or higher [26]. We also collected information about demographic characteristicsage, gender, and marital status; comorbid conditions-any infection, underlying active diseases, number of diseases, bladder or bowel incontinence, and bedfast; and clinical interventions-nutritional or hydration intervention to manage skin problems, turning or repositioning program, number of medications, and restraints.

In addition, four health index measures previously developed and validated for use with MDS instruments were obtained: the MDS Activities of Daily Living (ADL) Self-Performance Hierarchy [27]; the MDS Cognitive Performance Scale (CPS) [28, 29]; the MDS Depression Rating Scale (DRS) [30]; and the MDS Changes in Health, End-stage disease and Symptoms and Signs (CHESS) all reflecting resident health status in the last 7 days [31]. The ADL and CPS scores range from 0 to 6 , the DRS from 0 to 14 , and the CHESS is scored from 0 to 5 with higher values indicating higher levels of impairment. We also calculated the body mass index (BMI) based on height and weight recorded on the MDS.

\section{Statistical analysis}

General linear models were used to determine whether there was a significant difference in the mean MDS-HSI scores between residents with and without PU overall and stratified by measured resident characteristics. $T$-tests were used to compare mean scores in bivariate analyses with a bonferroni correction for multiple comparisons. MDS items considered as potential predictors of HRQOL were categorized into three groups: demographic characteristics; comorbid conditions; and clinical interventions. A full stepwise regression was performed wherein variables that showed a statistically significant $(p<0.01)$ and clinically important difference $( \pm 0.03)$ in MDS-HSI scores in bivariate comparisons between having the condition and not (either among residents with PU or among residents without PU) were used as potential explanatory variables in the model, with a probability level of 0.15 for entry and removal and MDS-HSI as the dependent variable. Demographic characteristics (age group, gender, and marital status) were forced to be retained in the model to control for relationships between these and other comorbidity variables and MDS-HSI scores. ADL and CPS were not included in the regression models because the underlying MDS items are used in the MDS-HSI algorithm. SAS was used for all analyses (SAS Inc, North Carolina, USA version 9.1).

\section{Results}

Characteristics of LTC residents

A total of 1,498 (9\%) of our sample of 16,531 LTC residents had a stage II or greater PU reported on their MDS assessment (Table 1). There were no significant differences in the length of stay or demographic characteristics (i.e. age and marital status) between residents with and without PU except that the proportion of males was higher in residents with PU (34 vs. $30 \%, p=0.001$ ). The mean \pm standard deviation (SD) BMI was significantly lower in residents 
Table 1 MDS-HSI of LTC residents by pressure ulcer status and demographic characteristics

\begin{tabular}{|c|c|c|c|c|c|c|c|}
\hline \multirow[t]{3}{*}{ Characteristics } & \multicolumn{3}{|c|}{ With pressure ulcer } & \multicolumn{3}{|c|}{$\begin{array}{l}\text { Without pressure } \\
\text { ulcer }\end{array}$} & \multirow{3}{*}{$\begin{array}{l}\text { MDS- } \\
\text { HSI } \\
\text { PU- } \\
\text { Diff }^{\text {a }}\end{array}$} \\
\hline & \multicolumn{3}{|c|}{ MDS-HSI } & \multicolumn{3}{|c|}{ MDS-HSI } & \\
\hline & $N(\%)$ & Mean & $\mathrm{SD}$ & $N(\%)$ & Mean & SD & \\
\hline Total number & 1,498 & 0.26 & 0.13 & 15,033 & 0.36 & 0.17 & -0.10 \\
\hline \multicolumn{8}{|c|}{ Age group (years) } \\
\hline$<75$ & $\begin{array}{l}178 \\
(12)\end{array}$ & 0.27 & 0.14 & $\begin{array}{r}1902 \\
(13)\end{array}$ & 0.39 & 0.18 & -0.12 \\
\hline $75-84$ & $\begin{array}{l}544 \\
(36)\end{array}$ & 0.26 & 0.14 & $\begin{array}{l}5499 \\
(37)\end{array}$ & 0.37 & 0.17 & -0.10 \\
\hline $85+$ & $\begin{array}{l}776 \\
(52)\end{array}$ & 0.25 & 0.13 & $\begin{array}{r}7632 \\
(51)\end{array}$ & 0.34 & 0.16 & -0.09 \\
\hline \multicolumn{8}{|l|}{ Gender } \\
\hline Male & $\begin{array}{l}508 \\
(34)\end{array}$ & 0.29 & 0.14 & $\begin{array}{r}4494 \\
(30)\end{array}$ & 0.38 & 0.18 & -0.10 \\
\hline Female & $\begin{array}{l}987 \\
\quad(66)\end{array}$ & 0.25 & 0.13 & $\begin{array}{r}10517 \\
(70)\end{array}$ & 0.34 & 0.17 & -0.10 \\
\hline \multicolumn{8}{|l|}{ Marital status } \\
\hline $\begin{array}{l}\text { Never } \\
\text { married }\end{array}$ & $91(6)$ & 0.28 & 0.14 & $1138(8)$ & 0.38 & 0.18 & -0.10 \\
\hline Other ${ }^{\mathrm{b}}$ & $\begin{array}{r}1407 \\
(94)\end{array}$ & 0.26 & 0.13 & $\begin{array}{r}13895 \\
(92)\end{array}$ & 0.35 & 0.17 & -0.10 \\
\hline
\end{tabular}

MDS-HSI Minimum Data Set-Health Status Index, SD standard deviation

${ }^{a}$ PU-Diff: All differences in MDS-HSI between residents with and without pressure ulcer are significant using a $t$-test, $p<0.001$

b Married, separated, widowed, or divorced

with PU than those without PU $(21.7 \pm 3.3$ vs. $22.7 \pm 2.8$, $p<0.001)$. Residents with PU were more likely to require extensive (41 vs. $26 \%$ ) or total (67 vs. $34 \%, p<0.001$ ) ADL assistance and have severe cognitive impairment (based on the CPS) (38 vs. $26 \%, p<0.001)$ than those without PU.

\section{Comorbid conditions and clinical interventions}

Results shown in Table 2 indicate that residents with PU were significantly more likely than those without PU to have a history of urinary (77 vs. $60 \% ; p<0.001$ ) or bowel (66 vs. $41 \% ; p<0.001)$ incontinence, and infection (22 vs. $11 \%$; $p<0.001)$. Residents with PU were also more likely to have a CHESS score of one or above ( 61 vs. $46 \% ; p<0.001)$ and weight loss (17 vs. $8 \% ; p<0.001)$. The mean \pm SD number of diseases was significantly greater in residents with PU than in those without PU $(4.6 \pm 2.3$ vs. $4.3 \pm 2.2$; $p<0.001)$. Frequencies of clinical interventions included in Table 3 show that residents with PU were significantly more likely than those without PU to have a history of receiving a nutritional or hydration intervention for skin problems (32 vs. $4 \% ; p<0.001$ ), being on a turning or repositioning program (52 vs. $15 \% ; p<0.001)$, receiving 12 or more medications ( 34 vs. $28 \% ; p<0.001$ ), or to be restrained on a daily basis ( 26 vs. $14 \% ; p<0.001$ ).

Health utilities: the Minimum Data Set-Health Status Index scores

The unadjusted means and SDs of the MDS-HSI by LTC residents' PU status and by their demographic characteristics, comorbid conditions, and clinical interventions, and the mean MDS-HSI differences between the two groups are reported in Tables 1 through 3. A statistically significant difference as well as clinically important difference $( \pm 0.03)$ in MDS-HSI between residents without PU and those with PU was observed in most variables. The unadjusted mean \pm SD MDS-HSI score of LTC residents without PU was $0.36 \pm 0.17$ and the MDS-HSI for those with PU was $0.26 \pm 0.13$. Similarly, a 0.10 -point or more difference in MDS-HSI between residents without PU and those with PU was also generally observed within levels of demographic variables. The MDS-HSI difference by PU status was also significant and approximately 0.10 points lower in the absence of comorbid conditions. However, the difference in MDS-HSI scores across PU status was smaller (0.05-0.07 points lower among residents with PU) in the presence of comorbid conditions such as incontinence, infections, higher CHESS scores, and weight loss. The difference in MDS-HSI scores between residents with and without PU was also smaller among residents receiving nutritional interventions, repositioning program, and nonsignificant among residents in daily restraints.

Factors associated with health utilities (MDS-HSI)

In the final stepwise regression model (Table 4), all variables with significant and clinically important differences in the univariate analysis were also retained by the stepwise procedure in the multivariate model with the exception of weight loss. Older age ( 85 years and older), being female, having a PU, history of having any infection $(p=0.034)$, having a hip fracture, having multiple diagnoses of chronic conditions (three or more), being bedfast, having bladder or bowel incontinence, higher CHESS scores, and clinically important depressive symptoms (depression scale score three or more) were negatively associated with MDS-HSI scores. Additionally, residents having received nutritional or hydration intervention ( $p=0.016$ ), a turning or repositioning program, antipsychotics, and restraints had lower MDS-HSI scores. Never being married was significantly associated with higher MDS-HSI scores. These factors explained $38 \%$ of the variance in the HRQOL. All 
Table 2 MDS-HSI of LTC residents by pressure ulcer status and comorbid conditions

\begin{tabular}{|c|c|c|c|c|c|c|c|}
\hline \multirow[t]{3}{*}{ Characteristics } & \multicolumn{3}{|c|}{ With pressure ulcer } & \multicolumn{3}{|c|}{ Without pressure ulcer } & \multirow{3}{*}{$\begin{array}{l}\text { MDS- } \\
\text { HSI } \\
\text { PU-Diff }\end{array}$} \\
\hline & \multicolumn{3}{|l|}{ MDS-HSI } & \multicolumn{3}{|l|}{ MDS-HSI } & \\
\hline & $N(\%)$ & Mean & $\mathrm{SD}$ & $N(\%)$ & Mean & $\mathrm{SD}$ & \\
\hline Total number & 1,498 & & & 15,033 & & & \\
\hline \multicolumn{8}{|l|}{ Bladder incontinence } \\
\hline Usually continent & $352(23)$ & 0.33 & 0.16 & $6002(40)$ & 0.45 & 0.18 & -0.12 \\
\hline Incontinent & $1146(77)$ & 0.24 & 0.11 & $9031(60)$ & 0.30 & 0.14 & -0.06 \\
\hline \multicolumn{8}{|l|}{ Bowel incontinence } \\
\hline Usually continent & $505(34)$ & 0.33 & 0.15 & $8806(59)$ & 0.42 & 0.17 & -0.09 \\
\hline Incontinent & $993(66)$ & 0.22 & 0.11 & $6227(41)$ & 0.27 & 0.13 & -0.05 \\
\hline \multicolumn{8}{|l|}{ Bedfast } \\
\hline No & $1328(89)$ & 0.27 & 0.13 & $14716(98)$ & 0.36 & 0.17 & -0.09 \\
\hline Yes & $170(11)$ & 0.19 & 0.10 & $317(2)$ & 0.24 & 0.12 & -0.05 \\
\hline \multicolumn{8}{|l|}{ Any infection } \\
\hline No & $1173(78)$ & 0.26 & 0.13 & $13354(89)$ & 0.36 & 0.17 & -0.10 \\
\hline Yes & $325(22)$ & 0.26 & 0.13 & $1679(11)$ & 0.32 & 0.15 & -0.07 \\
\hline \multicolumn{8}{|l|}{ Number of diseases } \\
\hline $0-2$ & $265(18)$ & 0.26 & 0.15 & $3137(21)$ & 0.38 & 0.19 & -0.12 \\
\hline $3-5$ & $768(51)$ & 0.26 & 0.13 & $7982(53)$ & 0.36 & 0.17 & -0.10 \\
\hline Six or more & $465(31)$ & 0.25 & 0.12 & $3914(26)$ & 0.33 & 0.15 & -0.08 \\
\hline \multicolumn{8}{|l|}{ Hip fracture } \\
\hline No & $1325(88)$ & 0.26 & 0.13 & $13844(92)$ & 0.36 & 0.17 & -0.10 \\
\hline Yes & $173(12)$ & 0.26 & 0.13 & $1189(8)$ & 0.31 & 0.15 & -0.05 \\
\hline \multicolumn{8}{|l|}{ CHESS } \\
\hline 0 & 579 (39) & 0.29 & 0.15 & $8068(54)$ & 0.38 & 0.18 & -0.10 \\
\hline 1 & 437 (29) & 0.26 & 0.12 & $4269(28)$ & 0.34 & 0.16 & -0.08 \\
\hline 2 & $286(19)$ & 0.24 & 0.12 & $1950(13)$ & 0.31 & 0.15 & -0.07 \\
\hline 3 & $126(8)$ & 0.22 & 0.11 & $577(4)$ & 0.26 & 0.12 & -0.04 \\
\hline $4-5$ & $70(5)$ & 0.17 & 0.08 & 169 (1) & 0.24 & 0.11 & -0.07 \\
\hline \multicolumn{8}{|l|}{ Depression scale } \\
\hline $0-2$ & $964(64)$ & 0.29 & 0.14 & $10284(68)$ & 0.39 & 0.17 & -0.10 \\
\hline Three or more & $534(36)$ & 0.20 & 0.10 & 4749 (32) & 0.28 & 0.13 & -0.07 \\
\hline \multicolumn{8}{|l|}{ Weight loss } \\
\hline No & 1037 (69) & 0.26 & 0.13 & $11979(80)$ & 0.36 & 0.17 & -0.10 \\
\hline Yes & $250(17)$ & 0.23 & 0.12 & $1183(8)$ & 0.29 & 0.15 & -0.06 \\
\hline
\end{tabular}

MDS-HSI Minimum Data Set-Health Status Index, SD standard deviation

${ }^{a}$ PU-Diff: difference in MDS-HSI between residents with and without pressure ulcer; $t$-test, $p$ value for each variable category $<0.001$ except CHESS score three category $(p=0.004)$. CHESS, Changes in Health, End-stage disease and Symptoms and Signs-higher values indicate higher levels of clinical instability and risk of death [31]

variables showed significance at a $p$ value $<0.001$ except those shown previously.

Factors with no additional significant effect

Although multiple chronic diagnoses have a significant effect on the residents' HRQOL, individual diagnosis of diabetes, hypertension, other heart problems, arthritis, osteoporosis, cerebrovascular accident, any psychiatric diagnosis, or eye problem had no significant effect on HRQOL in both residents with and without PU. Furthermore, the number of medications received, having received antianxiety, antidepressant, or antihypnotic medication, hospital stays, emergency room visits, and physician visits were not significantly associated with MDS-HSI scores. 
Table 3 MDS-HSI of LTC residents by pressure ulcer status and clinical intervention

\begin{tabular}{|c|c|c|c|c|c|c|c|}
\hline \multirow[t]{3}{*}{ Characteristics } & \multicolumn{3}{|c|}{ With pressure ulcer } & \multicolumn{3}{|c|}{ Without pressure ulcer } & \multirow{3}{*}{$\begin{array}{l}\text { MDS-HS } \\
\text { PU-Diff }^{a}\end{array}$} \\
\hline & \multicolumn{3}{|l|}{ MDS-HSI } & \multicolumn{3}{|l|}{ MDS-HSI } & \\
\hline & $N(\%)$ & Mean & SD & $N(\%)$ & Mean & SD & \\
\hline \multicolumn{8}{|c|}{ Nutritional intervention } \\
\hline No & $1026(68)$ & 0.27 & 0.13 & $11430(96)$ & 0.36 & 0.17 & -0.09 \\
\hline Yes & $472(32)$ & 0.23 & 0.12 & $603(4)$ & 0.26 & 0.14 & -0.03 \\
\hline \multicolumn{8}{|c|}{ Repositioning program } \\
\hline No & $716(48)$ & 0.30 & 0.15 & $12825(85)$ & 0.38 & 0.17 & -0.07 \\
\hline Yes & $782(52)$ & 0.22 & 0.10 & $2208(15)$ & 0.24 & 0.11 & -0.02 \\
\hline \multicolumn{8}{|c|}{ Number of medications } \\
\hline $0-5$ & $246(16)$ & 0.24 & 0.14 & $3002(20)$ & 0.36 & 0.18 & -0.12 \\
\hline $6-11$ & $749(50)$ & 0.26 & 0.13 & $7872(52)$ & 0.36 & 0.17 & -0.09 \\
\hline 12 or more & $503(34)$ & 0.27 & 0.13 & $4159(28)$ & 0.35 & 0.16 & -0.09 \\
\hline \multicolumn{8}{|l|}{ Antipsychotics } \\
\hline No & $1084(72)$ & 0.27 & 0.14 & $10306(69)$ & 0.37 & 0.17 & -0.10 \\
\hline Yes & $414(28)$ & 0.23 & 0.11 & $4727(31)$ & 0.33 & 0.17 & -0.10 \\
\hline \multicolumn{8}{|l|}{ Antianxiety } \\
\hline No & $1244(83)$ & 0.26 & 0.13 & $12533(83)$ & 0.36 & 0.17 & -0.10 \\
\hline Yes & 254 (17) & 0.25 & 0.13 & 2500 (17) & 0.34 & 0.17 & -0.09 \\
\hline \multicolumn{8}{|l|}{ Antidepressants } \\
\hline No & $936(62)$ & 0.26 & 0.13 & 8861 (59) & 0.37 & 0.17 & -0.10 \\
\hline Yes & $562(38)$ & 0.26 & 0.13 & $6172(41)$ & 0.34 & 0.16 & -0.09 \\
\hline \multicolumn{8}{|l|}{ Antihypnotics } \\
\hline No & $1402(94)$ & 0.26 & 0.13 & $13816(92)$ & 0.36 & 0.17 & -0.10 \\
\hline Yes & $96(6)$ & 0.26 & 0.14 & $1217(8)$ & 0.36 & 0.17 & -0.09 \\
\hline \multicolumn{8}{|l|}{ Daily restraints } \\
\hline No & $1113(74)$ & 0.28 & 0.14 & $12895(86)$ & 0.38 & 0.17 & -0.10 \\
\hline Yes & $385(26)$ & 0.21 & 0.09 & 2138 (14) & 0.22 & 0.10 & -0.01 \\
\hline
\end{tabular}

MDS-HSI Minimum Data Set-Health Status Index, SD standard deviation

${ }^{a}$ PU-Diff: difference in MDS-HSI between residents with and without pressure ulcer; $t$-test, $p$ value for each variable category $<0.001$ except daily restraint $(p=0.0491)$

\section{Discussion}

Our study showed that utility scores for LTC residents are low. The unadjusted sample mean MDS-HSI scores were significantly lower for LTC residents with PU than those without PU, with a moderate decrement of 0.10 in utility. This relationship was consistent within several demographic and clinical comorbid categories. PU was slightly $(-0.026)$ and significantly related to HRQOL independent of other resident demographic characteristics, comorbid conditions, and clinical interventions. Comorbidity contributed substantially to the low HRQOL in the study population.

Treatment and prevention of diseases and conditions are expensive. Cost-effectiveness analyses of health care interventions are increasingly used to inform health policy where quality of life measures are being incorporated. But costeffectiveness analyses often rely on low quality evidence.
For example, in the absence of empirical data, Fleurence et al. [2] in their cost-effectiveness analysis of pressurerelieving devices for the prevention and treatment of PUs, derived utility scores for PU health states via expert panel of five health professionals, using a rating scale technique. Population utilities based on community preference scores such as those presented here are more representative than utilities estimated by small panels of experts [2].

The weights used in the derivation of MDS-HSI are reflective of a community-based population and, therefore, might understate or overstate the LTC residents' own perceptions of their utility scores. Nonetheless, similar to the National Population Health Survey (NPHS, a prospective survey of the health of Canadians) population [32], utility scores in our LTC residents without PU decreased with increasing age and the number of comorbid conditions. The current MDS-HSI scores of LTC residents 
Table 4 Stepwise regression of factors associated with MDSHIS

\begin{tabular}{|c|c|c|c|}
\hline Variable & Coefficient & SE & $p$ Value \\
\hline Intercept & 0.520 & 0.004 & $<0.001$ \\
\hline Pressure ulcer status (II to IV vs. 0 to I) & -0.022 & 0.004 & $<0.001$ \\
\hline Age group (years)* & & & $<0.001$ \\
\hline$<75$ & Ref & & \\
\hline $75-84$ & -0.003 & 0.003 & 0.368 \\
\hline 85 or older & -0.018 & 0.003 & $<0.001$ \\
\hline Gender* (female vs. male) & -0.016 & 0.002 & $<0.001$ \\
\hline Never married (versus other)* & 0.018 & 0.004 & $<0.001$ \\
\hline Infection (yes vs. no) & -0.007 & 0.003 & 0.034 \\
\hline Hip fracture (yes vs. no) & -0.018 & 0.004 & $<0.001$ \\
\hline Number of diseases & & & $<0.001$ \\
\hline $0-2$ & Ref & & \\
\hline $3-5$ & -0.009 & 0.003 & 0.0008 \\
\hline Six or more & -0.018 & 0.003 & $<0.001$ \\
\hline Bedfast (yes vs. no) & -0.049 & 0.006 & $<0.001$ \\
\hline Bladder incontinence (yes vs. no) & -0.068 & 0.003 & $<0.001$ \\
\hline Bowel incontinence (yes vs. no) & -0.066 & 0.003 & $<0.001$ \\
\hline CHESS & & & $<0.001$ \\
\hline 0 & Ref & & \\
\hline 1 & -0.024 & 0.002 & $<0.001$ \\
\hline 2 & -0.041 & 0.003 & $<0.001$ \\
\hline 3 & -0.064 & 0.005 & $<0.001$ \\
\hline $4-5$ & -0.072 & 0.009 & $<0.001$ \\
\hline Depression scale (three or more vs. 0-2) & -0.082 & 0.002 & $<0.001$ \\
\hline Nutritional/hydration intervention (yes vs. no) & -0.011 & 0.005 & 0.016 \\
\hline Turning/repositioning program (yes vs. no) & -0.049 & 0.003 & $<0.001$ \\
\hline Antipsychotics (yes vs. no) & -0.014 & 0.002 & $<0.001$ \\
\hline Restraints (yes vs. no) & -0.071 & 0.003 & $<0.001$ \\
\hline
\end{tabular}

are also comparable to a previous study among residents in two LTC homes in Ontario (0.35) [15]. On the other hand, the average utility scores of LTC residents in this study (0.35) is substantially lower than those among communitydwelling populations with chronic conditions of similar age in the NPHS (e.g. urinary incontinence: 0.71) [32] or community-based older frail home care clients (0.60) [14, 15]. These differences may be explained by a higher prevalence of comorbid conditions in LTC residents when compared with community-based populations or by differences in the mode of assessment (i.e. observation versus self-report [16]).

There are a number of limitations to this analysis. First, the cross-sectional nature of our study limits assessment of changes in HRQOL over time. Second, the LTC MDS-HSI scores may not be generalizable to all people with PU in the community or to other LTC settings. Our sample includes only 89 of the over 600 LTC homes in Ontario. There is relatively little information available about the specific 89 homes except that they were selected by the health ministry to be representative of geography, ownership, and size (in order to provide the provincial ministry with evaluative information for planning and implementation lessons). Finally, the predictors in our models accounted for only $38 \%$ of the variability in LTC residents' HRQOL, and we were not able to accurately identify and adjust for facility factors or socioeconomic factors that might impact resident HRQOL.

\section{Conclusion}

In conclusion, our results suggest that the HRQOL of LTC residents is low and that PU has a slight though statistically significant impact on their HRQOL controlling for the effects of comorbid conditions and related treatments. These findings have implications for prevention and treatment of PUs. The MDS-HSI provides an important summary outcome measure for the economic evaluation of PU prevention and care among residents in LTC settings. Future research should examine longitudinal changes in HRQOL associated with the onset of and recovery from PU. 
Acknowledgments The authors thank Ba' Pham for his comments to the final draft of the manuscript. The Toronto Health Economics and Technology Assessment Collaborative is funded by the Ontario Ministry of Health and Long-Term Care and is affiliated with the Department of Health, Policy, Management and Evaluation, University of Toronto. The statements and conclusions are those of the authors and not of the Ministry. Data presented in part at the 30th Annual Meeting of the Society for Medical Decision Making, October 18-22, 2008, Philadelphia.

Open Access This article is distributed under the terms of the Creative Commons Attribution Noncommercial License which permits any noncommercial use, distribution, and reproduction in any medium, provided the original author(s) and source are credited.

\section{References}

1. Reddy, M., Gill, S. S., \& Rochon, P. A. (2006). Preventing pressure ulcers: A systematic review. The Journal of the American Medical Association, 296(8), 974-984.

2. Fleurence, R. L. (2005). Cost-effectiveness of pressure-relieving devices for the prevention and treatment of pressure ulcers. International Journal of Technology Assessment in Health Care, 21(3), 334-341.

3. National Pressure Ulcer Advisory Panel. (1989). Pressure ulcers prevalence, cost and risk assessment: Consensus development conference statement. Decubitus, 2, 24-28.

4. Fox, C. (2002). Living with a pressure ulcer: A descriptive study of patients' experiences. British Journal of Community Nursing, 7(6), 10, 2, 4, 6, 20, 2.

5. Langemo, D. K., Melland, H., Hanson, D., Olson, B., \& Hunter, S. (2000). The lived experience of having a pressure ulcer: A qualitative analysis. Advances in Skin \& Wound Care, 13(5), 225-235.

6. Spilsbury, K., Nelson, A., Cullum, N., Iglesias, C., Nixon, J., \& Mason, S. (2007). Pressure ulcers and their treatment and effects on quality of life: Hospital inpatient perspectives. Journal of Advanced Nursing, 57(5), 494-504.

7. Hopkins, A., Dealey, C., Bale, S., Defloor, T., \& Worboys, F. (2006). Patient stories of living with a pressure ulcer. Journal of Advanced Nursing, 56(4), 345-353.

8. Gold, M. R., Patrick, D. L., Torrance, G. W., Fryback, D. G., Hadorn, D. C., \& Kamlet, M. S. (1996). Identifying and valuing outcomes. In M. R. Gold, J. E. Siegel, L. B. Russell, M. C. Weinstein, et al. (Eds.), Cost-effectiveness in health and medicine (pp. 82-134). New York: Oxford University Press.

9. Hirdes, J. P., Fries, B. E., Morris, J. N., Steel, K., Mor, V., Frijters, D., et al. (1999). Integrated health information systems based on the RAI/MDS series of instruments. Healthcare Management Forum, 12(4), 30-40.

10. Dellefield, M. E. (2007). Implementation of the resident assessment instrument/minimum data set in the nursing home as organization: Implications for quality improvement in RN clinical assessment. Geriatric Nursing, 28(6), 377-386.

11. Fries, B. E., Schneider, D. P., Foley, W. J., Gavazzi, M., Burke, R., \& Cornelius, E. (1994). Refining a case-mix measure for nursing homes: Resource utilization groups (RUG-III). Medical Care, 32(7), 668-685.

12. Bos, J. T., Frijters, D. H., Wagner, C., Carpenter, G. I., FinneSoveri, H., Topinkova, E., et al. (2007). Variations in quality of home care between sites across Europe, as measured by home care quality indicators. Aging Clinical and Experimental Research, 19(4), 323-329.
13. Hirdes, J. P. (1997). Development of a crosswalk from the minimum data set 2.0 to the Alberta resident classification system. Healthcare Management Forum, 10(1):27-29, 3234.

14. Wodchis, W. P., Maxwell, C. J., Venturini, A., Walker, J. D., Zhang, J., Hogan, D. B., et al. (2007). Study of observed and selfreported HRQL in older frail adults found group-level congruence and individual-level differences. Journal of Clinical Epidemiology, 60(5), 502-511.

15. Wodchis, W. P., Hirdes, J. P., \& Feeny, D. H. (2003). Healthrelated quality of life measure based on the minimum data set. International Journal of Technology Assessment in Health Care, 19(3), 490-506.

16. Morris, J. N., Fries, B. E., Steel, K., Ikegami, N., Bernabei, R., Carpenter, G. I., et al. (1997). Comprehensive clinical assessment in community setting: Applicability of the MDS-HC. Journal of the American Geriatrics Society, 45(8), 1017-1024.

17. Phillips, C. D., \& Morris, J. N. (1997). The potential for using administrative and clinical data to analyze outcomes for the cognitively impaired: An assessment of the minimum data set for nursing homes. Alzheimer Disease and Associated Disorders, 11(Suppl 6), 162-167.

18. Sgadari, A., Morris, J. N., Fries, B. E., Ljunggren, G., Jonsson, P. V., DuPaquier, J. N., et al. (1997). Efforts to establish the reliability of the resident assessment instrument. Age and Ageing, 26(Suppl 2), 27-30.

19. Frederiksen, K., Tariot, P., \& De Jonghe, E. (1996). Minimum data set plus (MDS+) scores compared with scores from five rating scales. Journal of the American Geriatrics Society, 44(3), 305-309.

20. Furlong, W. J., Feeny, D. H., Torrance, G. W., \& Barr, R. D. (2001). The health utilities index (HUI) system for assessing health-related quality of life in clinical studies. Annals of Medicine, 33(5), 375-384.

21. Torrance, G. W., Feeny, D. H., Furlong, W. J., Barr, R. D., Zhang, Y., \& Wang, Q. (1996). Multiattribute utility function for a comprehensive health status classification system. Health utilities index mark 2. Medical Care, 34(7), 702722.

22. Feeny, D., Furlong, W., Boyle, M., \& Torrance, G. W. (1995). Multi-attribute health status classification systems. Health utilities index. Pharmacoeconomics, 7(6), 490-502.

23. Torrance, G. W., Furlong, W., Feeny, D., \& Boyle, M. (1995). Multi-attribute preference functions. Health utilities index. Pharmacoeconomics, 7(6), 503-520.

24. Drummond, M. (2001). Introducing economic and quality of life measurements into clinical studies. Annals of Medicine, 33(5), 344-349.

25. Black, J., Baharestani, M., Cuddigan, J., Dorner, B., Edsberg, L., Langemo, D., et al. (2007). National pressure ulcer advisory panel's updated pressure ulcer staging system. Dermatology Nursing, 19(4), 343-349. Quiz 50.

26. Berlowitz, D. R., Brandeis, G. H., Morris, J. N., Ash, A. S., Anderson, J. J., Kader, B., et al. (2001). Deriving a risk-adjustment model for pressure ulcer development using the minimum data set. Journal of the American Geriatrics Society, 49(7), 866871.

27. Morris, J. N., Fries, B. E., \& Morris, S. A. (1999). Scaling ADLs within the MDS. Journals of Gerontology. Series A, Biological Sciences and Medical Sciences, 54(11), M546-M553.

28. Hartmaier, S. L., Sloane, P. D., Guess, H. A., Koch, G. G., Mitchell, C. M., \& Phillips, C. D. (1995). Validation of the minimum data set cognitive performance scale: Agreement with the mini-mental state examination. Journals of Gerontology. Series A, Biological Sciences and Medical Sciences, 50(2), M128-M133. 
29. Morris, J. N., Fries, B. E., Mehr, D. R., Hawes, C., Phillips, C., Mor, V., et al. (1994). MDS cognitive performance scale. Journal of Gerontology, 49(4), M174-M182.

30. Burrows, A. B., Morris, J. N., Simon, S. E., Hirdes, J. P., \& Phillips, C. (2000). Development of a minimum data set-based depression rating scale for use in nursing homes. Age and Ageing, 29(2), 165-172.
31. Hirdes, J. P., Frijters, D. H., \& Teare, G. F. (2003). The MDSCHESS scale: A new measure to predict mortality in institutionalized older people. Journal of the American Geriatrics Society, 51(1), 96-100.

32. Mittmann, N., Trakas, K., Risebrough, N., \& Liu, B. A. (1999). Utility scores for chronic conditions in a community-dwelling population. Pharmacoeconomics, 15(4), 369-376. 